Research Paper

\title{
Artesunate Induces SKM-1 Cells Apoptosis by Inhibiting Hyperactive $\beta$-catenin Signaling Pathway
}

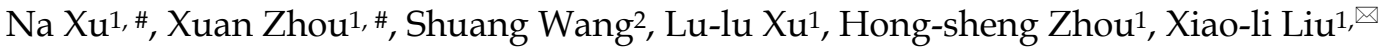 \\ 1. Department of Hematology, Nan fang Hospital, Southern Medical University, Guangzhou, China \\ 2. Department of Ultrasound, Xiangtan Central Hospital, Xiangtan, Hunan, China. \\ \# $\mathrm{Na} \mathrm{Xu}$ and Xuan Zhou contributed equally to this study
}

$\square$ Corresponding author: Xiao-li Liu, M.D, Department of Hematology Nan fang Hospital, Southern Medical University, 1838 Guangzhou Avenue North, Guangzhou 510515, P.R. China. Email: 1xlnf@126.com; Tel/fax: +86 02061641616

() 2015 Ivyspring International Publisher. Reproduction is permitted for personal, noncommercial use, provided that the article is in whole, unmodified, and properly cited. See http://ivyspring.com/terms for terms and conditions

Received: 2014.12.15; Accepted: 2015.05.13; Published: 2015.06.11

\begin{abstract}
Introduction: Artesunate (ART), a wildly used agent to treat severe malarial around the world, also has the power to inhibit growth of different types of tumor. However, the exact molecular mechanisms keep unknown. Method: In this study, we used myelodysplastic syndrome (MDS) cells (SKM-1 cells) with differential ART concentrations treatment at multiple time points to observe the subsequence cell function alteration and the possible involved pathway genes. Results: We found that ART demonstrated the ability to inhibit proliferation and induce apoptosis in SKM-1 in a dose and time-dependent manner. Demethylase recovered CDHI gene expression may be involved in the apoptosis process. The $\beta$-catenin protein translocated from the nucleus and cytoplasm to the membrane result in inactivation of $\beta$-catenin signaling pathway. Conclusion: Our findings provide a rational basis to develop ART as a useful therapeutic agent for the treatment of myelodysplastic syndromes.
\end{abstract}

Key words: Artesunate (ART); $\beta$-catenin pathway; E-cadherin; myelodysplastic syndrome

\section{Introduction}

The myelodysplastic syndromes are characterized with differentia ability inhibition in hematopoietic progenitor cells. Almost $30 \%$ of MDS patients will eventually convert into acute myeloid leukemia (AML) with poor prognosis defined by bone marrow blasts level [1]. Although research has been ongoing to obtain more detailed information to improve MDS treatment and prognosis, most current treatments only alleviate the symptoms and therefore novel treatments are urgently needed.

Dysregulation of the Wnt/ $\beta$-catenin pathway is highly implicated in the pathogenesis of many tumors including leukemia and MDS [2,3]. In normal cells, $\beta$-catenin is located in the membrane as part of cell-cell adhesion complexes to transmit the contact inhibition signal that signals cells to stop dividing. However, in tumor cells, $\beta$-catenin translocates to the nucleus losing its ability to trigger transcription of its target genes. This translocation turns tumor cells into invasive cells that eventually contribute to metastasis [4]. The E-cadherin gene (CDH1), located on chromosome 16q22, worked as tumor suppressor and modulated by the cytoplasmic proteins $\alpha-, \beta-$, and $\gamma$-catenin [5]. Emerging studies suggest that $\mathrm{CDH} 1$ gene promoter polymorphism and its methylation may be a good marker for evaluating the prognosis of patients with MDS [6-9]. Hypermethylation for CDH1 promoter region was observed in MDS patients and this methylation was reported to correlate with poor prognosis [10]. Since methylation is a reversible epigenetic change, developing a potential demethylating anticancer compound in MDS is feasible. In this study we investigated the therapeutic effect of ART on CDH1 promoter methylation status.

ART is a well-known anti-malarial which derived from artemisinin, an extract of Artemisia annual 
(artemisinin) [11]. Recent studies reported ART to be a promising tumor therapy candidate for many types of tumors. It potentially triggers apoptotic cell death in doxorubicin-resistant T-leukemia cells[11], cervical cancer cells in conjunction with radiation[12], and induces apoptosis in MDS cell lines SKM-1 through caspase-dependent and independent pathways, although the mechanisms remain largely unknown[13]. In addition, ART was found to attenuate cell growth and inhibit the hyperactive $\mathrm{Wnt} / \beta$-catenin pathway in human colorectal carcinoma [4]. A recent report indicated that ART significantly inhibited proliferation of the MDS cells [13]. The mechanism by which ART exudes its anti-tumor role in MDS still needs further exploration.

The SKM-1 cell line preserves the MDS and leukemic phases and is the most common tool used to study MDS. In this investigation, we treated SKM-1 cells with ART to explore the effects of ART on apoptosis and proliferation and investigated the possible signaling pathway involved in this anti-tumor mechanism.

\section{Materials and methods}

\section{Cells Culture}

The SKM-1 cell line was purchased from the Cell Collection of Chinese Academy of Sciences (Shanghai, China). Cells were cultured in RPMI1640 supplied with $10 \%$ calf serum, and incubated at $37{ }^{\circ} \mathrm{C}$ with $5 \%$ $\mathrm{CO}_{2}$, and used at the logarithmic growth phase.

\section{Growth inhibition assay}

MTT [3-(4, 5-dimethylthiazol-2-yl)-2, 5-diphenyltet-razolium bromide] (Sigma, USA) assay was used to assess cell proliferation. The SKM-1 cells $\left(1 \times 10^{5} / \mathrm{mL}\right)$ were firstly seeded in 96 -well plates. ART (Sigma, USA) was diluted in $0.1 \%$ dimethyl sulfoxide (DMSO) producing $0,12.5,25,50 \mu \mathrm{g} / \mathrm{mL}$ concentrations and added to the SKM-1 cells with $100 \mu \mathrm{l}$ per well. A negative control was treated with $0.1 \%$ DMSO. At 0, 24, 48, and 72 hours, same amount of MTT solution was added into each well and cultured for extra 4 hours. MTT treated cells was fixed with 150 $\mu \mathrm{L}$ DMSO for $30 \mathrm{~min}$ at room temperature and then determined with Evolution 201 and 220 UV-Vis spectrophotometer system (Thermo Scientific, China) at $540 \mathrm{~nm}$.

\section{Apoptosis assessment}

After 48 hours ATR-treated $(0,12.5,25$, $50 \mu \mathrm{g} / \mathrm{mL}$ ), cells were collected and washed with cold Phosphate Buffered Saline (PBS). Apoptosis kits including propidium Iodide (PI) and fluorescein isothiocyanate (FITC)-annexin V work solution were purchased from Life science (Life science, USA).
Staining cells were analyzed by FACSCalibur ${ }^{\mathrm{TM}}$ flow cytometer (BD Biosciences, CA, USA) and analyzed using the CellQuest software (BD Biosciences, CA, USA). Early apoptotic cells percentage (stained with annexin $\mathrm{V}$ only) and late apoptotic cells percentage (stained with both annexin V and PI) was recorded. Further Hoechst33342 staining solution was used to identify apoptotic cells and detected with fluorescence microscopy (Olympus TXM-500C, Japan). Unstained cells were included as control.

\section{Methylation-specific PCR (MSP)}

Total cell genomic DNA was extracted using QIAamp DNA Mini KIT (Qiagen, China). CDH1 gene promoter region methylation status including 112bp unmethylation product and $120 \mathrm{bp}$ methylation product were determined using MSP as previous description [14]

Primers for Unmethylation:

Forward:

5'-TGTAGTTACGTATTTATTTTTAGTGGCGTC-3', Reverse:

5'-CGAATACGATCGAATCGAACCG-3' .

Primers for Methylation:

Forward:

5' '-TGGTTGTAGTTATGTATTTTAGTGGTGTT-3'

Reverse:

5'-ACACCAAATACAATCAAATCAAACCAAA-3'.

PCR conditions were as follows: $95^{\circ} \mathrm{C}$ for $10 \mathrm{~min}$, 35 cycles of $94^{\circ} \mathrm{C}$ for $30 \mathrm{~s}, 58^{\circ} \mathrm{C}$ for $40 \mathrm{~s}, 72^{\circ} \mathrm{C}$ for $30 \mathrm{~s}$, followed by $4 \mathrm{~min}$ at $72^{\circ} \mathrm{C}$. The products of the MSP were kept at $4^{\circ}$ Cand directly visualized under UV illumination by loading onto $1.5 \%$ agarose gel,

\section{Western blot analysis}

SKM-1 cells were treated with different concentrations of ART $(0,12.5,25,50 \mu \mathrm{g} / \mathrm{mL})$ for $48 \mathrm{~h}$, washed with cold PBS and harvested. Total protein was extracted with lysis buffer and resolved by SDS-PAGE, then transferred to PVDF membranes. To eliminate background disturb, membranes was blocked in put into blocking solution (5\% low fat milk, $0.1 \%$ Tween 20 in PBS) at room temperature for 1 hour. Cells were then incubated with a mouse monoclonal primary antibody specific for E-cadherin (ab76055), $\beta$-catenin(ab22656), c-myc(ab17365), cyclinD1 (ab10540) and GAPDH (ab9483) (Abcam, Cambridge, MA, USA; $1: 400)$ at $4^{\circ} \mathrm{C}$ overnight and followed by incubation with a secondary antibody (Abcam, Cambridge, MA, USA; 1:1,000) for $2 \mathrm{~h}$ at room temperature.. Enhanced chemiluminescence (ECL) was performed for protein analysis.

\section{Laser scanning confocal microscopy detected $E$-cadherin and $\beta$-catenin localization}

Laser scanning confocal microscopy (LSCM) was 
performed for E-cadherin and $\beta$-catenin localization in SKM-1 cells with differential ART concentration treatment. SKM-1 cells in logarithmic growth phase was incubated in 6-well plates containing coverslips overnight for cell adherent, AKT $(0,12.5,25$, $50 \mu \mathrm{g} / \mathrm{mL}$ ) was then added into culture medium and treated $48 \mathrm{~h}$. Cells was fixed in $4 \%$ paraformaldehyde at room temperature for 20min, PBS washed 3 times. And then blocked with 5\% BSA (containing 0.2\% Triton X-100) for $1 \mathrm{~h}$. Cells was next incubated with primary monoclonal antibody for E-cadherin and $\beta$-catenin (Abcam, Cambridge, MA, USA; 1:400) following by FITC-labeled secondary antibody (1:500) and then mounted. Laser scanning confocal microscope (LSM 510, Zeiss, Germany) was performed.

\section{Statistical Analysis}

SPSS 13.0 software was used for all data analysis. Numerical data are represented as the mean \pm standard deviation (SD). The difference between control and treated cells was determined by Student's t-test and ANOVA Each experiment was performed in triplicates. $p<0.05$ was considered as statistically significant

\section{Results}

\section{Inhibition of cell growth along with induced apoptosis following ART treatment in SKM-1 cells}

ART treatment dramatically inhibited the growth of SKM-1 cells in a dose and time-dependent manner (Fig. 1). The $\mathrm{IC}_{50}$ values were $61.18,38.39$, and
$28.56 \mu \mathrm{g} / \mathrm{mL}$ for ART treatments of 24,48 , and72 h, respectively. ART-induced apoptosis cell percentage was detected by flow cytometry (Fig. 2). The apoptotic rate of SKM-1 cells treated with ART increased in a dose-dependent manner, and the percentage of apoptotic cells was $25.35 \%, 52.75 \%$, and $60.4 \%$ when treated with ART at concentrations of 12.5, 25, $50 \mu \mathrm{g} / \mathrm{mL}$, which is significantly higher than the control group (3.98\%, p<0.05) (Fig 2A and 2B). Moreover, Hoechst33342 staining also identified considerable apoptosis in cells treated with ART (Fig. 2C). The apoptosis cell percentage with Hoechst33342 staining is $15.1 \%$ in $0 \mu \mathrm{g} / \mathrm{mL}$ ART treatment group, $23.3 \%$ in $12.5 \mu \mathrm{g} / \mathrm{mL}$ ART treatment group, $46.8 \%$ in $25 \mu \mathrm{g} / \mathrm{mL}$ ART treatment group and $61.7 \%$ in $50 \mu \mathrm{g} / \mathrm{mL}$ ART treatment group.

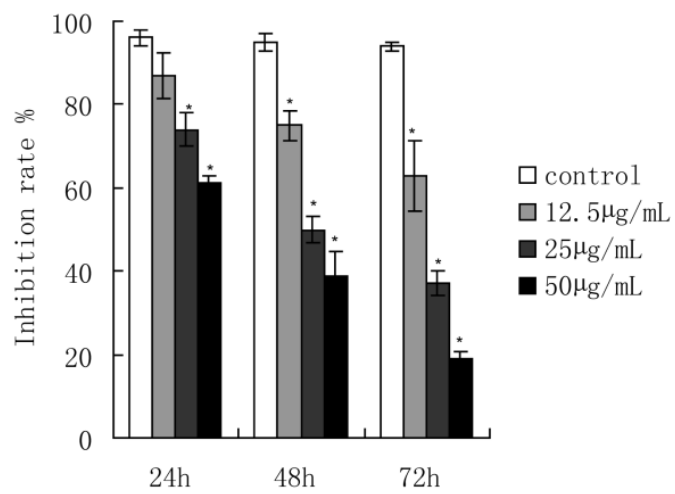

Fig. 1. The effect of ART on SKM-1 cells proliferation. Cells were treated with $0,12.5,25$ and $50 \mu \mathrm{g} / \mathrm{mL}$ of ART for 24,48 and 72 hours, and measured by MTT assay. The data represented the means \pm SD from three independent experiments. ${ }^{*} \mathrm{p}<0.05$ and ${ }^{* *} \mathrm{p}<0.01$ vs. the control group.

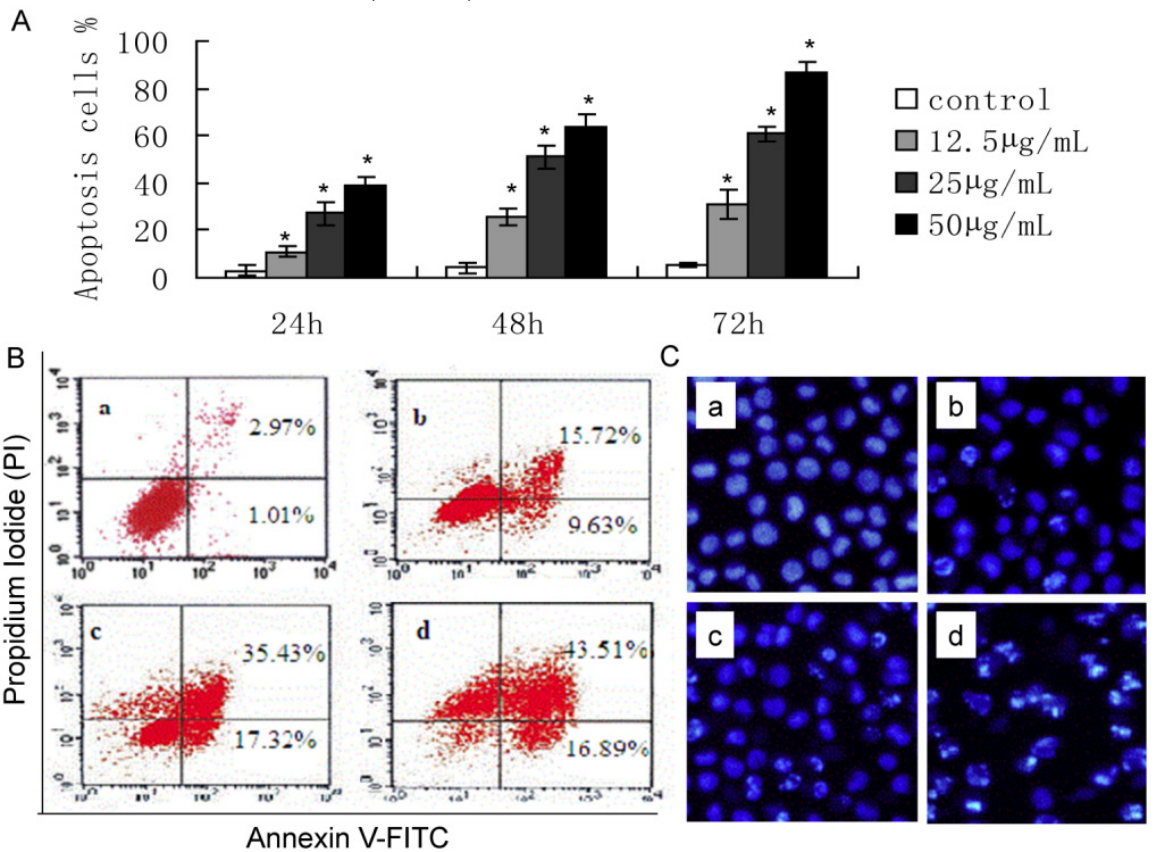

Fig. 2. The effect of ART on apoptosis of SKM-1 cells. A. Percentage of apoptotic cells when cells were treated with different concentration of ART for 24,48 and 72 hours. ${ }^{*} p<0.05$ and $* p<0.01$ vs. the control group. B. Early apoptotic cells (lower right quadrant) and late apoptotic cells (upper right quadrant) were analyzed

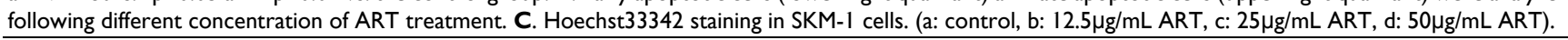




\section{Effect of ART on CDHI gene expression}

The CDH1 gene can be detected in methylated MSP products but is absent in non-methylated products of SKM-1 cells. It was seen only in the control group of methylated MSP products (Lane 3 compared to Lane 1, Fig 3). Notably, when cells were treated with $50 \mu \mathrm{g} / \mathrm{mL}$ ART for $48 \mathrm{~h}, \mathrm{CDH} 1$ gene was expressed under non-methylated conditions (Lane 2, Fig 3), but disappeared under methylated MSP conditions (Lane 4, Fig 3), which suggests that ART may contribute to the removal of the Methyl group from $\mathrm{CDH} 1$ gene, thus promoting CHD1 gene expression.

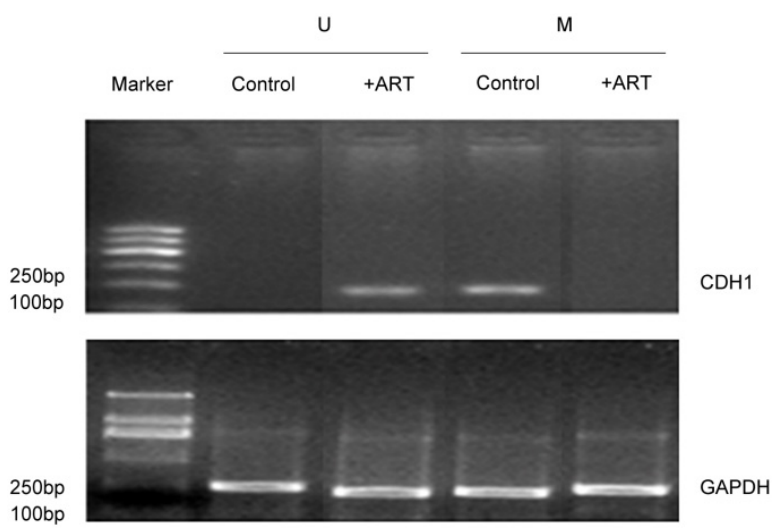

Fig. 3. The effect of ART on CDHI gene expression. MSP method was used to detect $C D H 1$ gene expression. SKM-1 cells were treated with $50 \mathrm{~g} / \mathrm{mL}$ concentration ART for 48h. $U$ and $M$ represent PCR results using methylated and unmethylated primers, respectively.

\section{Effect of ART on E-cadherin, $\beta$-catenin, c-myc and cyclinDI protein level}

In order to investigate the inhibitory effect of ART on the Wnt/ $\beta$-catenin pathway, we treated SKM-1 cells for $48 \mathrm{~h}$, and found that E-cadherin was induced from $12.5 \mu \mathrm{g} / \mathrm{mL}$ treatment, and over

Fig. 4. Effects of ART on protein expression in $W n t / \beta$-catenin pathway. Cell was harvested after different concentration of ART treatment for 48h, then E-caderin, $\beta$-catenin, c-myc and cyclin DI was extracted from the whole cell lysis and determined by western blot. A. Quantification of protein expression level; B. Protein expression images. GAPDH was used as control. expression with increasing ART concentrations (Fig 4, $\mathrm{P}<0.05)$, while $\beta$-catenin protein expression in whole cell lysis had no statistical change. We also identified the downstream target of Wnt/ $\beta$-catenin pathway, c-myc and cyclinD1, and we found c-myc and cyclinD1 protein levels decreased from $25 \mu \mathrm{g} / \mathrm{mL}$ after ART treatment (Fig 4, P<0.05) Furthermore, this decrease seems to negatively correlate with E-cadherin protein expression level. This may indicate that ART inhibited the Wnt/ $\beta$-catenin signaling pathway by resuming the loss of E-cadherin expression in SKM-1cells.

\section{Effect of ART on E-cadherin/ $\beta$-catenin subcelluar localization}

Since aberrant E-cadherin/ $\beta$-catenin localization also frequently occurs in MDS patients [15], we were interested to determine if the anti-tumor effect of ART was associated with E-cadherin/ $\beta$-catenin localization alterations. We found the E-cadherin signal on the membrane was triggered when cells were treated with $12.5 \mu \mathrm{g} / \mathrm{mL}$ ART, and distinctly accumulated on the membrane in $50 \mu \mathrm{g} / \mathrm{mL}$ ART treatment group after $48 \mathrm{~h}$ (Fig $5 \mathrm{~A}$ ). $\beta$-catenin localization confirmed by laser scanning confocal microscopy (LSCM), and $\beta$-catenin was visualized both in the nucleus and cytoplasm (Fig 5B, panel a). When we treated cells with different concentrations of ART $(0,12.5,25$, $50 \mu \mathrm{g} / \mathrm{mL}), \beta$-catenin expression gradually attenuated in the nucleus and cytoplasm while becoming more apparent on the membrane after $48 \mathrm{~h}$ (Fig 5B, panel b, $c, d)$. The overall intensity remained the same in both untreated and treated groups, which is consistent with $\beta$-catenin expression level in whole cell lysis.

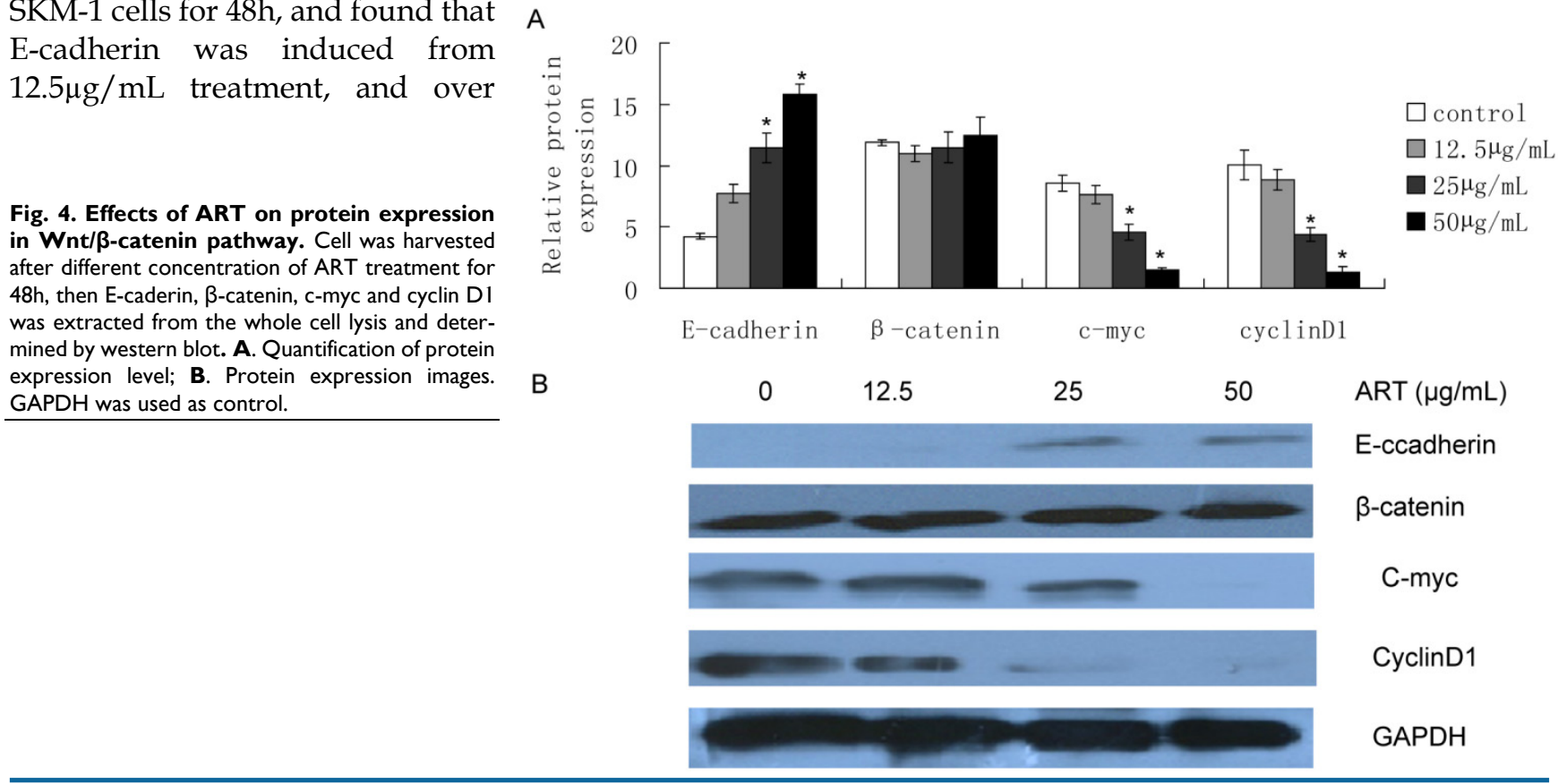



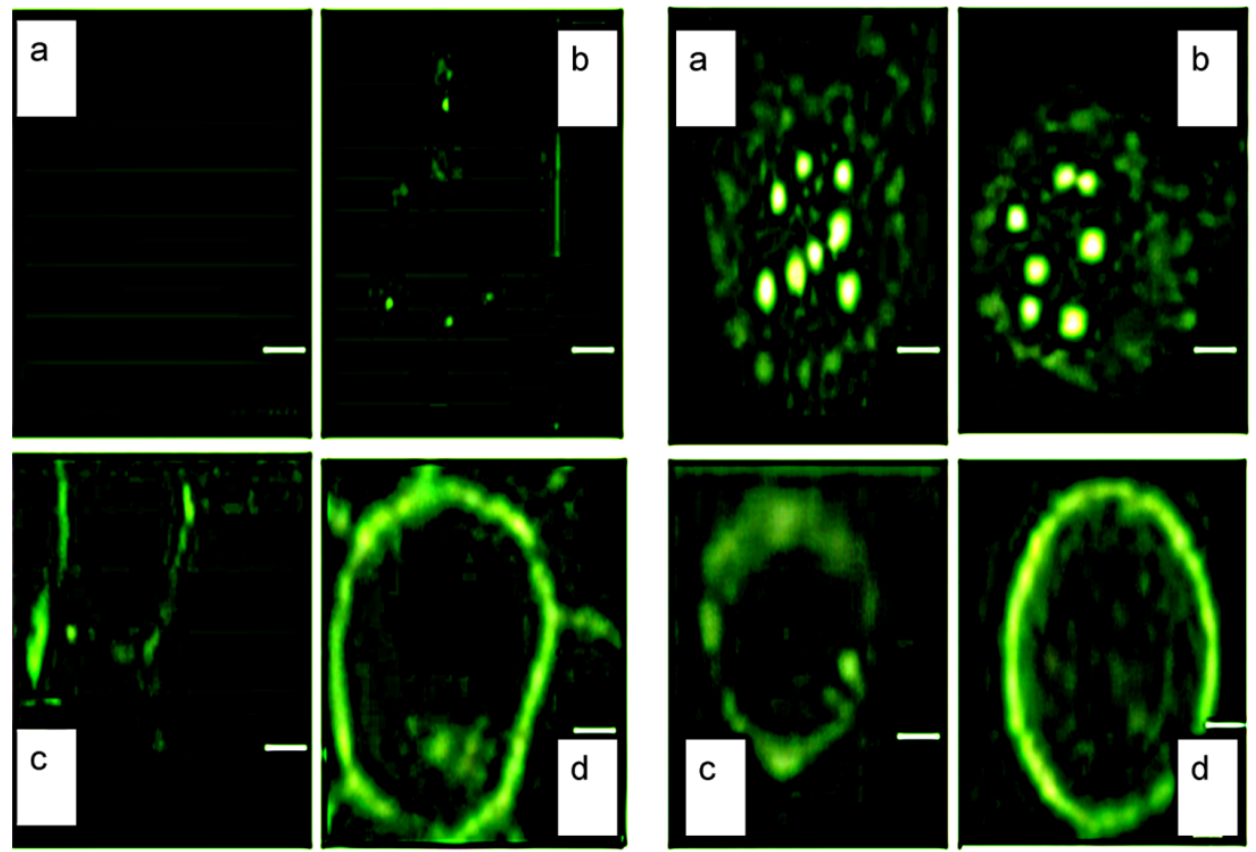

A:E-cdherin location

B:ß-catenin location

Fig. 5. LSCM was used to detect E-cadherin and $\beta$-catenin subcellular localization. Cells were fixed after different concentration of $A R T$ treatment for

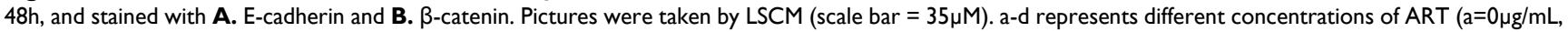
$\mathrm{b}=12.5 \mu \mathrm{g} / \mathrm{mL}, \mathrm{c}=25 \mu \mathrm{g} / \mathrm{mL}, \mathrm{d}=50 \mu \mathrm{g} / \mathrm{mL}$ ).

\section{Discussion}

From our study, we found ART could inhibit proliferation and induce apoptosis in SKM-1 cells in a dose-dependent and time-dependent manner (Fig 1 and 2). The $\mathrm{IC}_{50}$ value of ART decreased as the treatment period increased. ART inhibiting proliferation and inducing apoptosis was reported in numerous tumors [16-17]. This anti-tumor effect relates to the inhibitory effect on the hyperactive $\mathrm{Wnt} / \beta$-catenin pathway in human colorectal carcinoma, in which mRNA levels of c-myc were decreased after ART treatment [4]. Our findings in SKM-1 cells are in agreement with this study, and we also found ART treatment inhibited $W n t / \beta$-catenin downstream expression of targets such as c-myc and cyclinD1. C-myc and cyclinD1 are the proto-oncogenes involved in regulating proliferation, differentiation and apoptosis [18].

In this study, we found SKM-1 cells lost E-cadherin expression (Fig 4, Lane 1). We found the E-cadherin gene (CDH1) in these cells remained highly methylated (Fig 3, Lane 3), and the CDH1 methylation occurred in high frequencies in MDS [1]. The profile of CpG island hypermethylation is an epigenetic phenomenon and plays an important role in MDS and the global DNA methylation often predicts overall survival in MDS [9]. Notably, when we treated cells with $50 \mu \mathrm{g} / \mathrm{mL}$ ART for $48 \mathrm{~h}$, the silenced
E-cadherin gene (CDH1) "woke up" and recovered the un-methylated MSP product (Fig 3, Lane 2). We also found the E-cadherin protein was expressed more as ART concentrations increased (Fig 4, Lane 2-4) and gradually accumulated in the membrane (Fig $5 \mathrm{~A}$, panel $\mathrm{b}-\mathrm{d}$ ). Our data strongly suggest that ART could function as a demethylating agent to remove the methyl group from CDH1 genes, thus restoring the E-cadherin protein expression. In the past few years, demethylating agents like Azacitidine and Decitabine, have been approved by the U.S. Food and Drug Administration (FDA) as common drugs in care of MDS [19]. In view of its non-observed side effect profile [20], ART could also be a promising demethylating agent used for MDS therapy possibly with fewer side effects than the other currently available drugs.

Using LSCM we were able to visualize the $\beta$-catenin location in the cytoplasm and the nucleus (Figure 5B, panel a), indicating that this could be one feature of the Wnt pathway activation [21 22]. Being expressed in the nucleus, $\beta$-catenin could bind with lymphoid enhancing binding factor-1/T-cell factor-4 (LEF-1/TCF-4) $[23,24]$. This also could be a reason to sequester E-cadherin protein expression [23]. Strikingly, when we treated SKM-1 cell with ART, both $\beta$-catenin and E-cadherin translocated from the nucleus to the membrane, thereby forming the $\beta$-catenin/E-cadherin complex and strengthening 
cell-cell adhesion. They also further inhibited the epithelial to mesenchymal transition (EMT), which is recognized as an important event in malignancy. Several studies have demonstrated that $\beta$-catenin/E-cadherin complex is implicated in cancer chemoresistance [24, 25]. B-catenin/E-cadherin complex recruits Nrf2 and inhibits Nrf2 nuclear localization and transcriptional activity, thus making cancer cell more sensitive to anti-cancer therapy [25]. This ART-induced $\beta$-catenin and E-cadherin redistribution may help cancer cells decrease drug resistance and promote apoptosis of SKM-1 cells by inhibiting the hyperactive $\mathrm{Wnt} / \beta$-catenin pathway.

In summary, ART treatment demethylated CDH1, which, in turn recovers the E-cadherin activation in SKM-1 cells. Furthermore, by inhibiting the Wnt/ $\beta$-catenin pathway, the translocation of subcelluar $\beta$-catenin and E-cadherin to adherent junctions of the membrane enhances cell adhesion and inhibits metastasis and may also enhance chemo-sensitivity to other clinical agents. The expression of Wnt/ $\beta$-catenin downstream targets; c-myc and cyclinD1, also diminished causing tumor cell growth inhibition and increased apoptosis. Thereby these anti-tumor effects caused by ART may be a promising therapeutic drug for MDS therapy.

\section{Acknowledgements}

This study was supported by National Natural Science Foundation of China (No. 81170521) and Science Foundation of Nan fang Hospital (No.2012Z013)

\section{Conflict of Interest}

The authors declare that there are no conflicts of interest.

\section{References}

1. Aggerholm A, Holm MS, Guldberg P, et al. Promoter hypermethylation of p15INK4B, HIC1, CDH1, and ER is frequent in myelodysplastic syndrome and predicts poor prognosis in early-stage patients. Eur J Haematol. 2006; 76: 23-32.

2. Scheller M, Schönheit J, Zimmermann $K$, et al. Cross talk between Wnt/beta-catenin and Irf8 in leukemia progression and drug resistance. J Exp Med. 2013; 210: 2239-56.

3. Shuai X, Zhou D, Shen T, et al. Overexpression of the novel oncogene SALL4 and activation of the Wnt/beta-catenin pathway in myelodysplastic syndromes. Cancer Genet Cytogenet. 2009; 194: 119-24.

4. Li LN, Zhang HD, Yuan SJ, et al. Artesunate attenuates the growth of human colorectal carcinoma and inhibits hyperactive Wnt/beta-catenin pathway. Int J Cancer. 2007: 121: 1360-5.

5. Nagafuchi A, Takeichi M. Cell binding function of E-cadherin is regulated by the cytoplasmic domain. EMBO J.1988; 7:3679-84.

6. Asiaf A, Ahmad ST, Aziz SA, et al. Loss of expression and aberrant methylation of the CDH1 (E-cadherin) gene in breast cancer patients from Kashmir. Asian Pac J Cancer Prev. 2014; 15: 6397-403.

7. Wang H, Fan R, Wang XQ, et al. Methylation of Wnt antagonist genes: a useful prognostic marker for myelodysplastic syndrome. Ann Hematol. 2013; 92: 199-209.

8. Fu HY, Wu DS, Zhou HR, et al. CpG island methylator phenotype and its relationship with prognosis in adult acute leukemia patients. Hematology. $2014 ; 19$ : 329-37.

9. Calvo X, Nomdedeu M, Navarro A. High levels of global DNA methylation are an independent adverse prognostic factor in a series of 90 patients with de novo myelodysplastic syndrome. Leuk Res. 2014; 38: 874-81.
10. Greco M, D'Alò F, Scardocci A. Promoter methylation of DAPK1, E-cadherin and thrombospondin-1 in de novo and therapy-related myeloid neoplasms. Blood Cells Mol Dis.2010; 45: 181-5.

11. Efferth T, Giaisi M, Merling A, et al. Artesunate induces ROS-mediated apoptosis in doxorubicin-resistant T leukemia cells. PLoS One. 2007; 2: e693.

12. Luo J, Zhu W, Tang Y. Artemisinin derivative artesunate induces radiosensitivity in cervical cancer cells in vitro and in vivo. Radiat Oncol. 2014; 9: 84.

13. Wang $\mathrm{Y}$, Yang J, Chen L, et al. Artesunate induces apoptosis through caspase-dependent and -independent mitochondrial pathways in human myelodysplastic syndrome SKM-1 cells. Chem Biol Interact. 2014; 219C: 28-36.

14. Corn PG, Heath RH, Fogt F, et al. Frequent hypermethylation of the $5^{\prime} \mathrm{CpG}$ island of E-Cadherin in esophageal adenocarcinomas. Clin Cancer Res. 2001; 7:2765-2769.

15. Roman-Gomez J, Cordeu L, Agirre X. Epigenetic regulation of Wnt-signaliing pathway in acute lymophoblastic leukemia. Blood. 2007; 109: 3462-9.

16. Li S, Xue F, Cheng Z, et al. Effect of artesunate on inhibiting proliferation and inducing apoptosis of SP2/0 myeloma cells through affecting NFkappaB p65. Int J Hematol. 2009; 90: 513-21.

17. Hideshima T, Chauhan D, Podar K, et al. Novel therapies targeting the myeloma cell and its bone marrow microenvironment. Semin Oncol. 2001; 28:607-12.

18. Li YJ, Wei ZM, Meng YX, et al. Beta-catenin up-regulates the expression of cyclinD1, c-myc and MMP-7 in human pancreatic cancer: relationships with carcinogenesis and metastasis. World J Gastroenterol.2005; 11: 2117-23.

19. Jabbour E, Garcia-Manero G. Deacetylase Inhibitors for the Treatment of Myelodysplastic Syndromes. Leuk Lymphoma.2014; 1: 26.

20. Benakis A, Paris M, Loutan L, et al. Pharmacokinetics of artemisinin and artesunate after oral administration in healthy volunteers. Am J Trop Med Hyg. 1997; 56: 17-23.

21. Willert K, Jones KA. Wnt signaling: is the party in the nucleus? Genes Dev. 2006; 20: 1394-404

22. Behrens J, Lustig B. The Wnt connection to tumorigenesis. Int J Dev Biol.2004; 48: 477-87.

23. Papadavid E, Pignatelli M, Zakynthinos S, Krausz T, Chu AC. Abnormal immunoreactivity of the E-cadherin/catenin (alpha-, beta-, and gamma-) complex in premalignant and malignant non-melanocytic skin tumours. J Pathol. 2002; 196: 154-62.

24. Nakamura T, Kato $\mathrm{Y}$, Fuji $\mathrm{H}$, et al. E-cadherin-dependent intercellular adhesion enhances chemoresistance. Int J Mol Med. 2003; 12: 693-700.

25. Kim WD, Kim YW, Cho IJ, et al. E-cadherin inhibits nuclear accumulation of Nrf2: implications for chemoresistance of cancer cells. J Cell Sci. 2012; 125:1284-95. 